Discussion Paper Series A No.504

\title{
The Consumption-Wealth Ratio, Real Estate \\ Wealth, and the Japanese Stock Market
}

\author{
Kohei Aono \\ (College of Business Administration, Ritsumeikan University) \\ and \\ Tokuo Iwaisako \\ (The Institute of Economic Research, Hitotsubashi University)
}

July, 2008

The Institute of Economic Research Hitotsubashi University

Kunitachi, Tokyo, 186-8603 Japan 


\title{
The Consumption-Wealth Ratio, Real Estate Wealth, and the Japanese Stock Market
}

\author{
Kohei Aono (Ritsumeikan University) \\ Tokuo Iwaisako (Hitotsubashi University)
}

July 13, 2008 


\title{
The Consumption-Wealth Ratio, Real Estate Wealth, and the Japanese Stock Market ${ }^{\dagger}$
}

Kohei Aono, College of Business Administration, Ritsumeikan University.

Tokuo Iwaisako*, Institute of Economic Research, Hitotsubashi University.

July 2008

\begin{abstract}
The first contribution of this paper, following the works of Lettau and Ludvigson (2001a,b), is construction of the Japanese consumption-wealth ratio data series and to examine whether it explains Japanese stock market data. We find that the consumptionwealth ratio does not predict future stock returns, but it does help to explain the cross-section of Japanese stock returns. The second contribution of the paper is that we propose new consumption-wealth ratios in terms of which we more explicitly deal with household real estate wealth utilizing Japanese aggregate level data. Such "real estate augmented" consumption-wealth ratios work in a similar way, but perform better than, the consumption-wealth ratio calculated with only financial wealth data. While the scaled factor model with the consumption-wealth ratio proposed by Lettau and Ludvigson performs relatively well with Japanese data, the book-to-market related anomaly pointed out by Jagannathan et al. (1998) remains strong.

JEL Classification: E21, G12. Keywords: consumption-wealth ratio; cointegration; cross-section of stock returns.

$\dagger$ The previous version of this paper was circulated under the title of "The ConsumptionWealth Ratio and the Japanese Stock Market". We made substantial changes to the calculation of the variables used in the empirical analyses in this current version. We thank (including those who commented on the previous version) Toni Braun, Kei-ichi Hori, Takatoshi Ito, Toshiki Jinushi, Ryuzo Miyao, Makoto Saito, Masahiko Shibamoto, Hitoshi Takehara, Kenji Wada, Tsutomu Watanabe, the seminar participants at Hitotsubashi University, Kobe University, Tokyo Macro Workshop at University of Tokyo, Institute of Statistical Research, NFA annual meeting, 2007 Japanese Economic Association meeting, and Asian FA/NFA 2008 International Conference for their comments. Go Inoue provided able research assistance. Iwaisako greatly acknowledges financial assistance from the Japan Society for Promotion of Science 18330067.
\end{abstract}

* Corresponding author. E-mail: <iwaisako@ier.hit-u.ac.jp> 


\section{Introduction}

The consumption-based model is among the most important benchmarks in asset pricing models in financial economics. Yet, its empirical performance with a structural Euler equation using aggregate consumption data has been a major disappointment (see Campbell [2003] for a recent survey). Hence, recent studies started looking into different aspects of the consumption-based model. One attractive research strategy is to use disaggregate consumption data, which has been explored by authors such as Mankiw and Zeldes (1991) and Vissing-Jorgensen (2002). More recent studies including Lettau and Ludvigson (2001a,b), Parker and Julliard (2005), and Yogo (2006) examine, using aggregate data, long-run restrictions implied by consumption-based models, and they obtain useful results. In particular, Lettau and Ludvigson (2001a,b) consider the long-run cointegration relationship between consumption and household wealth. They propose to use the "cay" variable, which is in essence the consumption-wealth ratio of the household sector, in both predicting aggregate stock returns and explaining cross-sectional patterns of the US stock market.

We examine whether Lettau and Ludvigson's framework works with Japanese data in this paper. As we discuss in detail, there is a significant difference in the Japanese and US definition of household wealth regarding the treatment of real estate, so that Japanese data is not and cannot be fully comparable with the US data used by Lettau and Ludvigson. Although there are some other studies examining the same problems in the Japanese market, we take advantage of our familiarity with the data here ${ }^{1}$. We carefully construct a Japanese consumption/financial wealth data set and propose three alternative "cay" variables. Then, we test whether our "cay"s forecast future stock returns (Lettau and Ludvigson [2001a]) and whether they help to explain cross-sectional stock

\footnotetext{
${ }^{1}$ There are at least two other unpublished papers examining Lettau and Ludvigson's framework with Japanese data. Gao and Huang (2004) examine similar topics to those we are examining in this paper. However, our data construction is much closer to that of Lettau and Ludvigson. Therefore, there are significant differences between our empirical results and those of Gao and Huang. Matsuzaki (2003) uses a Japanese data set that is very similar to ours. However, his definition of consumption is slightly different from ours. This allows him to examine aggregate stock return predictability using a longer data series. He did not find any significant predictability in stock returns for his full sample or the subsample corresponding to our full sample. Therefore, his results on return predictability are consistent with our findings. On the other hand, Matsuzaki does not examine cross-sectional patterns. Neither Gao and Huang (2004) nor Matsuzaki (2003) include real estate wealth in their analysis.
} 
returns (Lettau and Ludvigson [2001b]). We obtain a negative result for the first question, but a positive result for the second question.

Of the three "cay" variables we propose, the first one totally ignores household real estate wealth. Of the other two, one treats real estate wealth separately from financial wealth and also uses land price data that is supposedly closer to the actual transaction price than the data used for the other "cay." Although all three "cay"s provide similar empirical results, such differences in definitions allow us to examine the relative importance of real estate wealth in the consumption-based pricing model. The empirical results of this paper suggest that considering real estate wealth separately from financial wealth improves the usefulness of "cay" in explaining a cross-section of Japanese stock returns ${ }^{2}$.

The remainder of this paper is organized as follows. In Section 2, we summarize the framework proposed by Lettau and Ludvigson and make some extensions. Section 3 discusses how the data is constructed and "cay" is calculated for Japan. Section 4 presents our main empirical results. Section 5 provides concluding remarks.

\section{Analytical framework}

Lettau and Ludvigson (2001a,b) use the cointegration among consumption, nonhuman wealth, and human wealth to draw various implications for stock returns. In this section, we first summarize their framework and then extend it for the analysis of the Japanese data.

\subsection{Lettau and Ludvigson's basic framework}

The argument by Lettau and Ludvigson starts from the following general intertemporal budget constraint:

$$
W_{t+1}=\left(1+R_{w, t+1}\right)\left(W_{t}-C_{t}\right),
$$

\footnotetext{
${ }^{2}$ In a related context, Lustig and Van Nieuwerburgh (2005) and Lustig et al. (2007) pointed out that real estate values reported from FRB are imprecise and problematic.
} 
where $W_{t}$ is total wealth and $C_{t}$ is the consumption of households. Applying the log-linear approximation (Campbell [1991]; Campbell and Shiller [1988]) to (1), we get the following relationship:

$$
\begin{aligned}
\Delta w_{t+1} & \approx k+r_{w, t+1}+\left(1-1 / \rho_{w}\right)\left(c_{t}-w_{t}\right) \\
\rho_{w} & \equiv \overline{(W-C) / W},
\end{aligned}
$$

where lowercase letters are natural logs of the variables in equation (1) and log return on total wealth, i.e., $r_{w, t+1} \equiv \ln \left(1+R_{w, t+1}\right)$.

The difference equation (2) is solved forward assuming the following "no bubble" condition:

$$
\lim _{i \rightarrow \infty} \rho_{w}^{i}\left(c_{t+i}-w_{t+i}\right)=0 .
$$

After some calculations, the following expression for the ex post log consumptionwealth ratio $c_{t}-w_{t}$ is obtained:

$$
c_{t}-w_{t}=\sum_{i=1}^{\infty} \rho_{w}^{i}\left(r_{w, t+1}-\Delta c_{t+i}\right)
$$

When consistency of investors' expectations is assumed, the following ex ante expression must also hold:

$$
c_{t}-w_{t}=\mathrm{E}_{t} \sum_{i=1}^{\infty} \rho_{w}^{i}\left(r_{w, t+1}-\Delta c_{t+i}\right) .
$$

To draw empirical implications, Lettau and Ludvigson assume that household total wealth consists of nonhuman wealth $a_{t}$ and human wealth $h_{t}$, i.e., the net present value of the future labor income stream:

$$
w_{t} \approx \omega a_{t}+(1-\omega) h_{t}
$$

Later, we extend this definition of household wealth to deal with real estate wealth more explicitly.

Under the assumption of (5), the log return on total household wealth is written as follows:

$$
r_{w, t} \approx \omega r_{a, t}+(1-\omega) r_{h, t} .
$$

Because human wealth $h_{t}$ cannot be observed, Lettau and Ludvigson assume it is a linear function of current labor income $y_{t}$, so that $h_{t}=\kappa+y_{t}+z_{t}$, where 
$z_{t}$ is a random noise term. Substituting (5) into the ex ante budget constraint (4) and substituting out $h_{t}$ using $y_{t}$, we obtain the following:

$$
\begin{aligned}
& c_{t}-\omega a_{t}-(1-\omega) y_{t} \\
= & \mathrm{E}_{t} \sum_{i=1}^{\infty} \rho_{w}^{i}\left\{\left[\omega r_{a, t+i}+(1-\omega) r_{h, t+i}\right]-\Delta c_{t+i}\right\}+(1-\omega) z_{t} .
\end{aligned}
$$

All right-hand side variables in (7) are stationary, so the sum of the left-hand side should be stationary too. This implies that we have a stationary relationship among $\left\{c_{t}, a_{t}, y_{t}\right\}$. Lettau and Ludvigson estimate the cointegration regression corresponding to the left-hand side of (7) and obtain the variable cayt as its residual:

$$
\operatorname{cay}_{t} \equiv c_{t}-\omega a_{t}-(1-\omega) y_{t} .
$$

Because $\omega$ is not time varying, this is essentially the log consumption-wealth ratio, in which the total wealth of households is defined by the sum of financial and human wealth.

Lettau and Ludvigson (2001a,b) estimate (8) by the dynamic least squares technique of Stock and Watson (1993), which specifies a single equation taking the following form:

$$
\begin{aligned}
c_{t}= & \alpha+\beta_{a} a_{t}+\beta_{y} y_{t} \\
& +\sum_{i=-k}^{k} b_{a, i} \Delta a_{t-i}+\sum_{i=-k}^{k} b_{y, i} \Delta y_{t-i}+\epsilon_{t},
\end{aligned}
$$

where $\Delta$ denotes the first difference operator. We denote the estimated trend deviation by $\widehat{c a y}=c_{t}-\hat{\beta_{a}} a_{t}-\hat{\beta_{y}} y_{t}$, where "hats" denote estimated parameters.

\subsection{Some extensions for Japanese data}

Because of the differences in the coverage of Japanese data, we have to be careful in applying Lettau and Ludvigson's framework. In their original works, $a_{t}$ is net nonhuman wealth calculated from FRB's Flow of Funds Accounts for US data. Hence, real estate wealth and corresponding liabilities are actually included in their measure of household net worth. On the other hand, the Bank of Japan's Flow of Funds data does not include real estate wealth, while it does 
include housing loans on the liability side of the household sector balance sheet. Hence, we cannot calculate Japanese household net wealth and $\widehat{c a y}$ that exactly corresponds to those in Lettau and Ludvigson for the US.

So we examine three different net wealth definitions and corresponding $\widehat{c a y}$ variables in this paper. First, we simply ignore the omission of real estate wealth in the Japanese data and use only financial net wealth, which includes housing loans. Let us denote this net financial wealth variable by $F W_{t}^{3}$. Then, the log of net nonhuman wealth $a_{t}$ in (7) and (8) is replaced by $f w_{t}=\ln F W_{t}$ in actual calculation of our first $\widehat{c a y}$ variable:

$$
\widehat{\operatorname{cay}}(1)=c_{t}-\hat{\beta}_{a} f w_{t}-\hat{\beta}_{y} y_{t} .
$$

This $\widehat{c a y}(1)$ corresponds to the $\widehat{c a y}$ variables used in Matsuzaki (2003) and Gao and Huang (2004) in our understanding.

For the other two $\widehat{c a y}$ variables, we explicitly deal with real estate wealth in calculating household net nonhuman wealth. Let us denote household real estate holdings by $R W_{t}$. In our second approach, we use national real estate wealth valuations in the System of National Accounts (SNA) data reported annually for our data of $R W_{t}$. We fill in missing observations using simple spline interpolations. Then, the calculated real estate wealth and financial wealth are summed to obtain the series for log total nonhuman wealth, $a w_{t}=\ln \left(F W_{t}+\right.$ $\left.R W_{t}\right)$. We use the $a w_{t}$ series to calculate our second $\widehat{c a y}$ variable:

$$
\widehat{\operatorname{cay}}(2)=c_{t}-\hat{\beta}_{a} a w_{t}-\hat{\beta}_{y} y_{t} \text {. }
$$

Conceptually, $\widehat{c a y}(2)$ is the closest to the definition of Lettau and Ludvigson's $\widehat{c a y}$ for the US. However, our procedure used to calculate the $R W_{t}$ series is admittedly very crude because three out of four observations of real estate wealth are interpolated.

In our third approach, we use the urban area land price index (Shigaichikakaku-shisu) tabulated by the Japan Real Estate Institute (JREI). The coverage of JREI's index is narrower than the coverage in the SNA data and is

\footnotetext{
${ }^{3}$ Another possibility is to exclude housing loans from liabilities and deal with pure net financial wealth. However, for older sample periods, housing loans and other liabilities are not separated in the Bank of Japan's flow of funds data.
} 
concentrated in urban areas. However, it is reported more frequently, on a semiannual basis, at the end of March and September each year. It is also widely believed that the characteristics of the JREI's index are much closer to those of the transaction data than the SNA data of real estate wealth, so that it is more widely used in previous research on Japanese land prices. We denote JREI's index by $U X_{t}$ and include its natural log $u x_{t}$ separately in the cointegration regression, as a wealth component independent of both financial $f w_{t}$ and human wealth $y_{t}$. Then, we estimate the four-variable cointegration system to obtain our third cayt $_{t}$ series:

$$
\widehat{c a y}(3)=c_{t}-\hat{\beta}_{a} f w_{t}-\hat{\beta}_{y} y_{t}-\hat{\beta}_{u x} u x_{t}
$$

We have to be careful in interpreting the usefulness of $\widehat{c a y}(2)$ and $\widehat{c a y}(3)$ as predictive variables or risk factors, because we use interpolated data series in our calculations. However, at least for $\widehat{c a y}(3)$, the empirical results reported below are unchanged even if we use the dummy variable instead of interpolation in our calculation ${ }^{4}$.

There are some additional reasons why explicitly dealing with real estate data such as in the estimation of $\widehat{c a y}(3)$ will be an important addition to the existing research. First, among those who are interested in the Japanese macro economy, it is widely believed that the land price bubble and its bursting have been a major source of Japanese economic stagnation in the last 15 years. Hence, investigating the role of real estate wealth in explaining financial asset returns will be of interest to many researchers. Second, while US flow of funds data include real estate wealth, some recent studies such as Lustig and Van Nieuwerburgh (2005) and Lustig et al. (2007) attempt to calculate a better measure of real estate wealth. So utilizing existing aggregate measures of Japanese real estate wealth will shed some new light on the research in this area.

\footnotetext{
${ }^{4}$ We calculate the alternate $\widehat{c a y}(3)$ using dummy variables as follows: From the original semiannual JREI index data, we first calculate the semiannual $\widehat{c a y}(3)$ series for March and September observations. Then, we estimate asset pricing models using the ordinary FamaMacBeth procedure with quarterly data. In the first step, a quarter-lagged $\widehat{c a y}(3)$ is used for the June/December observations, with the additive dummy variable for the coefficient. This procedure gives essentially the same results as the empirical results reported in Section 4.2 using the interpolated $\widehat{c a y}(3)$.
} 


\section{Calculation of $\widehat{c a y}$}

Our consumption series $C_{t}$ is household expenditure on nondurables and services, excluding shoes and clothing. This definition of consumption follows the US benchmark of Lettau and Ludvigson (2001a,b). Our labor income data $Y_{t}$ is adjusted household income minus financial income. Both data series are taken from the Japanese Cabinet Office's Annual Report on National Accounts.

Financial wealth $F W_{t}$ is household net worth including housing loans measured at the end of each period, but not real estate wealth. The data are from the Bank of Japan's Flow of Funds. Real estate wealth data $R W_{t}$ used for the calculation of $\widehat{c a y}(2)$ correspond to the entry titled "Land and others (Tochi sono ta)" in national wealth data in the Annual Report on National Accounts. "Land and others" includes forests, mining, and fisheries as well as real estate. It is reported once a year, at the end of the calendar year.

In our third approach, we use the urban area land price index tabulated by the JREI in calculating $\widehat{c a y}(3)^{5}$. The JREI releases different types of indexes, and we use the one offering the widest coverage, the index of the "nation wide average" for "all purposes" for the series $U X_{t}$.

Unfortunately, our consumption series only goes back to 1970. On the other hand, the release of real estate wealth data $R W_{t}$ in the national wealth statistics is very slow and this limits the availability of recent data. Therefore, our full sample starts with the fourth quarter of 1970 and ends with the first quarter of 2005, a total of 126 observations. We also consider the subsample that starts from the first quarter of 1977, with 110 observations, because the cross-section data we use later starts from this date.

An additional problem arises in estimating $\widehat{c a y}(3)$ is that because $U X_{t}$ is a price index, it is difficult to fully rationalize the use of its per capita value. For this reason, we also estimate a cointegration regression for $\widehat{c a y}(3)$ using the aggregate variable. Cointegration regressions for $\widehat{\operatorname{cay}}(1)$ and $\widehat{c a y}(2)$ are estimated using both aggregate and per capita variables. However, we report only

${ }^{5}$ The data are available from JREI's website: http://www.reinet.or.jp/jreidata/a_shi/index.htm. 
the estimation results using the aggregate variables here, and later discussions confirm that $\widehat{c a y}(1)$ and $\widehat{c a y}(2)$ calculated from aggregate and per capita data are almost identical.

Table 1 reports full sample and subsample estimation results of the cointegration systems (9) for the three different $\widehat{\text { cays }}{ }^{6}$. All estimated coefficients in Table 1 have the expected signs and are statistically significant at the $5 \%$ level, except that the subsample estimate of $u x_{t}$ 's coefficient in panel (3) is significant only at the $10 \%$ level. The estimated coefficients are somewhat similar to each other for the full sample and subsamples.

\section{[Insert Table 1 here]}

In Table 2, we check the differences between the $\widehat{c a y}$ s estimated using the aggregate and per capita variables, and for the full sample and subsamples. Panel (1) reports the descriptive statistics of the calculated aggregate and per capita $\widehat{c a y}(1)$ and $\widehat{c a y}(2)$ and their correlations. We confirm that the calculated $\widehat{c a y}$ series are almost identical as risk factors. Of course the means are very different, but the standard deviations and autocorrelations are very close to each other. Correlations of the two estimated $\widehat{c a y}$ series are more than $95 \%$ in the full sample and more than $99 \%$ in the subsample starting 1977. In panel (2), we report the correlation matrix of the full sample and subsample $\widehat{c a y}$ series. The correlations between the full sample $\widehat{c a y}$ and the subsample $\widehat{c a y}$ are extremely high, 0.973 for $\widehat{c a y}(1), 0.988$ for $\widehat{c a y}(2)$, and 0.993 for $\widehat{c a y}(3)$. Given these results, we use the $\widehat{c a y}$ variables calculated from aggregate data for the subsample starting 1977 for the following empirical analyses. We choose subsample data because the reliable Japanese cross-section data we use later starts only from the late 1970s.

\section{[Insert Table 2 here]}

\footnotetext{
${ }^{6}$ Following Lettau and Ludvigson $(2001 \mathrm{a}, \mathrm{b})$, we adopt $k=8$. However, we obtain a very similar cayt series even when we use a different number of lags.
} 
Figure 1 plots the calculated $\widehat{c a y}$ series for the subsample after 1977. The three series are almost equally different from each other, but the $\widehat{c a y}(3)$ series using the JREI index is somewhat more different from the other two series. It is consistently lower in 1980 and is consistently higher since the mid 1990s than other series. Furthermore, the $\widehat{c a y}(3)$ series is the most volatile and exhibits the highest autocorrelation, as reported in panel (1) of Table 2.

\section{[Insert Figure 1 here]}

\section{Empirical results}

\subsection{Forecasting stock returns}

In this section, we examine whether cay helps forecast future stock returns and whether it helps to explain cross-sectional stock returns with Japanese data. First, we briefly discuss our empirical results in relation to the first question.

While Lettau and Ludvigson (2001a) find that $\widehat{c a y}$ predicts future stock returns in the US, we find this is not the case for Japan. In Table 3, we report the one-quarter forecast of stock returns using the different $\widehat{c a y}$ series and additional controls for the sample starting 1977. The full sample results starting 1970 are mostly the same regarding the performance of the $\widehat{c a y}$ series. The $\widehat{c a y}$ series are never significant if the lagged returns are included in the regression. Furthermore, the signs of the estimated coefficients are negative in all specifications for panel (1) financial wealth alone and panel (2) including the JREI index. This contradicts the model's implications and the empirical evidence for the US market. Overall, we find very little evidence that $\widehat{c a y}$ is useful in predicting future stock returns in the Japanese stock market.

\section{[Insert Table 3 here]}

However, we consider this result unsurprising. In the second half of the 1980s, Japan experienced a tremendous stock market boom of historical magnitude (Ito and Iwaisako [1996]). It was followed by a sharp decline in 1990-1992 
and prolonged stagnation through the 1990s, known as Japan's lost decade. Because the sample contains such a significant one-time boom and bust in stock prices, any study on Japanese aggregate stock returns including this period faces a major difficulty. We will reexamine this issue in subsection 4.3 , after we discuss our cross-sectional empirical results.

Among the additional controls, including the log price-dividend ratios $P D R$ seems to improve the forecastability even though the estimated coefficients are not statistically significant. The short-term interest rate variable $R R E L$ and the term-structure variable $T R M$ do not help forecast stock returns. Because the sample period includes the recent zero-interest rate policy period by the Bank of Japan and does not include any significant change in the inflation rate, these empirical results seem reasonable.

\subsection{Explaining cross-sectional stock returns}

Next, we examine whether $\widehat{c a y}$ helps to explain cross-sectional Japanese stock returns using 25 Fama-French portfolios. We use the data from Nikkei Media Marketing, whose data construction closely follows the series used by Keiichi Kubota and Hitoshi Takehara ${ }^{7}$. Our Fama-French factors, SMB and HML, are also constructed from this data set. We convert all asset returns and factor data to a quarterly basis to implement the empirical analysis using the $\widehat{c a y}$ variable.

Following Lettau and Ludvigson (2001b), we use the Fama-MacBeth twostep approach to examine the performances of alternative factors in explaining cross-sectional Japanese stock returns. In the first step, quarterly portfolio returns are regressed on alternative sets of factors $F_{t}$ and conditioning variables $Z_{t-1}$.

$$
r_{i, t}=\beta_{0}+F_{t} \beta_{1, i}+Z_{t-1} \beta_{2, i} . \quad i=1, . ., I
$$

Then, in the second step, average returns are regressed on the betas estimated in the first step:

$$
\begin{aligned}
E\left[r_{i, t}\right] & =E\left[r_{0, t}\right]+\widehat{\beta}_{i} \lambda \\
\widehat{\beta} & =\left[\widehat{\beta}_{1, i}, \widehat{\beta}_{2, i}\right] .
\end{aligned}
$$

${ }^{7}$ See Jagannathan et al. (1998) as an example of empirical papers written in English that uses Japanese Fama-French portfolio data constructed by Kubota and Takehara. 
Our risk factor $F_{t}$ includes market portfolio $(R v w)$, labor income growth $\Delta y_{t}$, and the Fama-French SMB and HML factors $(S M B$ and $H M L)$. As proposed by Lettau and Ludvigson (2001b), we include $\widehat{c a y}_{t-1}$ as the conditioning variable and also use it as a scaling variable to obtain the scaled factors, " $\widehat{c a y}_{t-1} \cdot R v w_{t}$ " and " $\widehat{c a y}_{t-1} \cdot \Delta y_{t}$ ".

We run and compare various specifications using the Fama-MacBeth twostep approach and the results are summarized in Table 4. In panel (A), the average returns of portfolios are reported in a $5 \times 5$ matrix. On average, realized returns are higher with the portfolios of smaller size and of higher B/P. However, within the same B/P groups, the ordering of average returns do not necessarily correspond to the firm size. Hence, the size effect seems to be limited and the effect of $\mathrm{B} / \mathrm{P}$ is much more prominent in the Japanese market.

Panels (B) and (C) show estimates of $\lambda_{s}$ in the second stage of the FamaMacBeth regressions for 25 Fama-French portfolios. Benchmark results for the Japanese data reported in panel (B) exhibit similarities to the US results. As with the US results, the static CAPM, the market portfolio $R v w_{t}$ alone, has very limited explanatory power for the cross-section of stock returns in the Japanese data (row 1). Adding the labor income $\Delta y_{t}$ significantly improves the performance (row 2). The Fama-French three-factor model (row 5) exhibits significant improvement of performance compared with the market model and even with the labor income augmented model.

\section{[Insert Table 4 here]}

However, when we consider the SMB and HML factors separately, we observe some clear differences between Japanese and US empirical results. In row 4 of Table 4, the combination of market portfolio and HML factor explain $70 \%$ of the cross-section of Japanese stock returns. On the other hand, the "market portfolio plus SMB" explains only $32 \%$ in row 3 . These patterns found in panel (A) and (B) are consistent with the findings by Jagannathan et al. (1998) about Fama-French factors in the Japanese market: Examining Jagannathan and Wang's (1996) conditional CAPM with Japanese data, they find that the size effect is absent in the Tokyo market. They also report that the HML factor 
is more effective in explaining cross-sectional patterns in Japanese than in US empirical results.

In panel $(\mathrm{C})$, we report the estimation results for "the scaled factor model", including " $\widehat{c a y}_{t-1} \cdot R v w_{t}$ " and " $\widehat{c a y}_{t-1} \cdot \Delta y_{t}$ " as suggested in Lettau and Ludvigson (2001b). We use three different $\widehat{\text { cays }}$ and the performance improves as each of $\widehat{c a y}(1), \widehat{c a y}(2)$, and $\widehat{c a y}(3)$ is used. This ordering is robust and does not change if the subsample data are examined and when a slightly different definition of the consumption series was used in the previous version of this paper. The result suggests that including the information about real estate wealth $(\widehat{c a y}(2)$ and $\widehat{c a y}(3))$ is important. The comparison of $\widehat{c a y}(2)$ and $\widehat{c a y}(3)$ suggests that treating real estate wealth separately from financial wealth and using the data close to the value of market transactions for real estate further improves the performance of the scaled factor model.

Panel (C) exhibits some similarities and differences with the US results regarding the roles of the consumption-wealth ratio. First, the scaled factor models perform much better than the static CAPM and the labor income augmented model as Lettau and Ludvigson (2001b) reported using US data. Admittedly, however, the scaled factor models' performances with Japanese data are not quite as impressive as the US results in terms of the comparison with the Fama-French benchmark: the Fama-French three factor model explains up to $80 \%$ of quarterly cross-sectional variation measured by $R^{2}$, both for the Japanese data (panel B, row 5) and US data (Lettau and Ludvigson [2001b], Table 1). In Lettau and Ludvigson's original work, the scaled factor model's performance for the US is very close to the Fama-French benchmark, explaining $75-77 \%$ of cross-sectional variation. With the Japanese data, they explain less than $70 \%$ in panel C, row $7-(3)$.

Second, the role of the conditional factor $\widehat{c a y}_{t-1}$ is somewhat more significant in the Japanese results. With all $\widehat{c a y}$ variables, the specification including $\widehat{c a y}$ separately performs better than without it. With $\widehat{c a y}(2)$ and $\widehat{c a y}(3)$, the differences in performance are very obvious. So $\widehat{c a y}_{t-1}$ affects the conditional expected returns of portfolios as well as the sensitivities of stock returns to risk factors in the Japanese data. 
Figures 2, 3, and 4 plot the fitted values of the second-stage regression against actual average returns for the CAPM, the Fama-French, and the scaled factor model with $\widehat{c a y}(3)$. As in the regression result in Table 4, the CAPM in Figure 4 is flat and exhibits almost no explanatory power. The remaining two figures exhibit some interesting differences. The Fama-French model explains the portfolio returns of the mid-level average return very well. On the other hand, even though the $R^{2}$ is lower than the Fama-French model, the scaled factor model has an advantage in pricing the portfolios with the highest and lowest average returns.

\section{[Insert Figures 2, 3, and 4 here]}

Table 5 compares the Fama-French factors and the scaled factor models more closely, concentrating on the cases with $\widehat{c a y}(3)$. Row 1 adds SMB and row 2 adds HML to the scaled factor model of Lettau and Ludvigson, but without $\widehat{c a y}(3)$ as a conditioning variable. The latter specification has more explanatory power, $R^{2}$ being around $90 \%$. This is not surprising as we have seen the significance of the HML factor and the absence of the size effect in Table 4. Row 3 adds the conditioning variable $\widehat{c a y}(3)$ and row 4 adds the SMB factor to row 2's specification. Neither of them seem to add additional information in explaining the cross-section of Japanese stock returns. The result in row 3 implies that the source of explanatory power of $\widehat{c a y}(3)$ somewhat overlaps with that of the HML factor in Japan.

\section{[Insert Table 5 here]}

Overall, the empirical results presented here suggest that the scaled factor model suggested by Lettau and Ludvigson (2001b) performs relatively well with Japanese data. It performs much better than the combination of the market index and SMB factor (Table 4, row 3) and very close to the specification including the market index and HML factor (row 4). However, the importance of the HML factor in the Japanese market does not diminish even in comparison with the scaled factor model. The book-to-market related anomaly pointed out 
by Jagannathan et al. (1998), in the context of the conditional CAPM with labor income, remains strong in our setting as well.

\subsection{Robustness check}

The empirical results for the cross-section returns in this paper perhaps requires robustness checks for two reasons. First, as observed from Figure 1, all $\widehat{c a y}$ variables have fluctuated wildly since the start of new millennium. This roughly corresponds to the period of significant fluctuations in the Japanese savings rate $^{8}$. We should be careful because the empirical results are significantly influenced by the observations in this period. Second, in all specifications in Tables 4 and 5 , the standard errors of the estimated parameters in the second step Fama-MacBeth procedure are very large so that the $t$ statistics are insignificant. This is partly attributable to the limited size of our quarterly data set, but Jagannathan et al. (1998) face the same problem even though they use monthly data. This may not be a concern; however, we will check the robustness of the results anyway.

Table 6 provides the second-stage regression results for the Fama-MacBeth regression, using a subsample ending at the fourth quarter of 2000. The subsample results are very similar to the full sample estimates. While the scaled factor model with $\widehat{c a y}(3)$ in row 4 performs better than the static CAPM and the labor income augmented models in the first two rows, it does not perform as well as the Fama-French three factor model in row 3. The combination of Lettau and Ludvigson's scaled factor model with the HML factor outperforms even the Fama-French model; however, the difference is smaller in the subsample. Overall, Table 6 confirms that the empirical results in Tables 4 and 5 hold for the subsample.

\footnotetext{
${ }^{8}$ Those who analyze recent Japanese savings rate fluctuations in the framework of dynamic general equilibrium models such as Chen et al. (2006) emphasize the "decline" of the savings rate, referring to the ageing population and productivity growth slowdown as the main sources of the "decline." However, as the Japanese economy has recovered from the recession in the mid 2000s, the savings rate has experienced substantial fluctuations.
} 


\subsection{Discussions}

While the consumption-wealth ratio $\widehat{c a y}$ helps to explain some aspects of Japanese stock returns, the way it contributes to the performance of the asset pricing model is somewhat different from the US result reported by Lettau and Ludvigson (2001b). Furthermore, the Japanese $\widehat{c a y}$ is not very useful in predicting future stock returns. Such US-Japan differences require some explanation.

The theoretical framework proposed by Lettau and Ludvigson imposes the "no bubble" condition (3) in deriving an expression for the log consumptionwealth ratio. This condition rules out rational "bursting bubble" type deviations from the fundamentals (Blanchard [1979]; Blanchard and Watson [1982]), in favor of time-varying expected returns. One possible interpretation of Japanese asset price bubbles in the late 1980s is that such a "no bubble" condition had been actually violated in this period. If so, the lack of predictive ability of the Japanese consumption-wealth ratio is not very surprising.

Alternatively, we may interpret large asset price fluctuations during the bubble period as a reflection of the fact that the stock market and household consumption are only loosely connected in Japan compared with the US. In this respect, Japan is not an outlier among developed economies. Correlations between stock returns and consumption growth are often very weak and sometimes even negative except for English-speaking countries, in particular Canada, the UK, and the US (see Campbell [2003], Table 4). Therefore, significant financial asset price appreciations can occur without causing a corresponding increase in consumption. Hence, the $\widehat{c a y}$ can deviate from the long-run equilibrium more persistently, because the adjustment process will require a much longer time to return back to the long-run equilibrium. Hence, stock returns may also be predictable in Japan for the very long run, for example, more than a five-year

period. Because our sample size is relatively small, statistical inference on such long-run predictability is extremely difficult.

We prefer this second interpretation because it is easier to justify the usage of the scaled factor model in explaining cross-sectional returns than the first model. Even if $\widehat{c a y}$ were not useful in predicting market returns in the immediate future, its movement might be capturing the longer-run change in market 
conditions that affects the time-variation of sensitivities to the risk factors. Both interpretations of the asset price bubble in the late 1980s provide sensible explanations for why $\widehat{c a y}$ is not very helpful in forecasting the short-run dynamics of the Japanese stock market. Unfortunately, they cannot be differentiated in the finite sample because both imply that asset prices eventually return to their fundamental values after a certain period of time.

\section{Concluding remarks}

In this paper, we examined whether the consumption-wealth ratio, $\widehat{c a y}$, can explain Japanese stock market data. We carefully construct three $\widehat{c a y}$ s that are each different in their treatment of real estate wealth. Unlike the US results, $\widehat{c a y}$ does not predict future Japanese stock returns. On the other hand, $\widehat{c a y}$ provides some help in explaining the cross-section of stock returns of FamaFrench portfolios. The scaled factor model with $\widehat{c a y}$ performs better than the labor income augmented CAPM and the combination of the market factor and SMB factor. However, even in our setting, the importance of the HML factor in explaining the Japanese cross-section of stock returns, first pointed out by Jagannathan et al. (1998), remains strong.

This paper primarily concentrates on the construction of Japanese $\widehat{\text { cays }}$ including real estate wealth data and the comparison of basic empirical results with existing US results in Lettau and Ludvigson (2001a,b). In future research, we would like to explore our empirical results in detail and examine their economic interpretations, including the different time-series behaviors of different $\widehat{\operatorname{cay} s}$.

In particular, while our $\widehat{c a y}(3)$ using the JREI index is the most useful of the three $\widehat{c a y} \mathrm{~s}$ we consider in this paper, we use the index offering the widest coverage in its calculation. It will be interesting to calculate $\widehat{c a y}$ using narrower JREI indexes such as more concentrated in usage (commercial/residential) and in regional coverage, because commercial land prices in large cities tend to be more sensitive to macroeconomic conditions. 


\section{References}

- Aono Kohei and Tokuo Iwaisako (2007). "The Consumption-Wealth Ratio and the Japanese Stock Market." Research Center for Price Dynamics, Institute of Economic Research, Hitotsubashi University, Working Paper Series, No. 9.

- Blanchard, Olivier Jean (1979) "Speculative Bubbles, Crashes and Rational Expectations," Economic Letters 3, 387-389.

- Blanchard, Olivier Jean and Mark Watson (1982) "Bubbles, Rational Expectations and Financial Markets," in Paul Wachtel (ed.), Crises in the Economic and Financial Structure, Lexington Books, 295-316.

- Campbell, John Y. (1991) "A Variance Decomposition for Stock Returns," Economic Journal 101, 157-179.

- Campbell, John Y. (2003) "Consumption-based Asset Pricing," Chapter 13 in G. M. Constantinides, M. Harris, and R. M. Stulz eds., Handbook of the Economics of Finance, Volume 1, Part 2, Financial Markets and Asset Pricing, 605-1246, Elsevier B.V.

- Campbell, John Y. and Robert J. Shiller (1988) "The Dividend-Price Ratio and Expectations of Future Dividends and Discount Factors," Review of Financial Studies 1, 195-228.

- Chen, K., Imrohoroglu, A., Imrohoroglu, S. (2006) "The Japanese Saving Rate," American Economic Review, 96(5), 1850-1858.

- Gao, Pengjie and Kevin X. D. Huang (2004) "Aggregate ConsumptionWealth Ratio and the Cross-Section of Stock Returns: Some International Evidence," FRB of Kansas City Working Paper No. RWP 04-07.

- Ito, Takatoshi and Tokuo Iwaisako (1996) "Explaining Asset Bubbles in Japan," Bank of Japan Monetary and Economic Studies 14, 143-193.

- Jagannathan, Ravi, Keichi Kubota, and Hitoshi Takehara (1998) "Relationship between Labor-income Risk and Average Return: Empirical Evidence from the Japanese Stock Market," Journal of Business 71, 319347. 
- Jagannathan, Ravi and Zhenyu Wang (1996) "The Conditional CAPM and the Cross-Section of Expected Returns, Journal of Finance 51, 3-53.

- Lettau, Martin and Sydney Ludvigson (2001a) "Consumption, Aggregate Wealth, and Expected Stock Returns" Journal of Finance 56, 815-49.

- Lettau, Martin and Sydney Ludvigson (2001b) "Resurrecting the (C)CAPM: A Cross-Sectional Test when Risk Premia are Time-Varying" Journal of Political Economy 109, 1238-87.

- Lettau, Martin and Sydney Ludvigson (2004) "Understanding Trend and Cycle in Asset Values: Reevaluating the Wealth Effect on Consumption," American Economic Review 94, 276-99.

- Lustig, Hanno N. and Stijn Van Nieuwerburgh (2005) "Housing Collateral, Consumption Insurance, and Risk Premia: An Empirical Perspective," Journal of Finance 60, 1167-1219.

- Lustig, Hanno N., Stijn Van Nieuwerburgh, and Adrien Verdelhan (2007) "The Wealth-Consumption Ratio: A Litmus Test for Consumption-based Asset Pricing Models," working paper, Department of Economics, UCLA.

- Mankiw, N. Gregory and Stephen P. Zeldes (1991) "The Consumption of Stockholders and Nonstockholders," Journal of Financial Economics 29, $97-112$.

- Matsuzaki, Arata (2003) "Predicting Japanese Stock Returns with Consumptionwealth Ratio (in Japanese)," Unpublished MA thesis, Graduate School of Economics, Hitotsubashi University.

- Parker, Jonathan A. and Christian Julliard (2005) "Consumption Risk and the Cross-Section of Expected Returns," Journal of Political Economy $113,185-222$.

- Stock, James H., and Mark W. Watson (1993) "A Simple Estimator of Cointegrating Vectors in Higher Order Integrated Systems," Econometrica $61,783-820$.

- Vissing-Jorgensen, Annette (2002) "Limited Asset Market Participation and the Elasticity of Intertemporal Substitution," Journal of Political Economy 110, 825-853. 
- Yogo, Motohiro (2006) "A Consumption-Based Explanation of Expected Stock Returns," Journal of Finance 61, 539-580. 


\section{Table 1 \\ Cointegration Regression for Calculating $\widehat{c a y}$}

Cointegrated systems including real estate wealth are estimated by the dynamic least squares method of Stock and Watson (1993) with eight leads and lags. Sample period is the first quarter of 1977 to the fourth quarter of 2004. The left-hand side variable is $c_{t}$, household expenditure on nondurables and services, excluding shoes and clothing. $f w_{t}$ is the household net financial wealth in the Bank of Japan flow of funds data. $a w_{t}$ is the sum of financial wealth and stock value of land in the SNA data. $u x_{t}$ is the urban land price index of the Japan Real Estate Institute (nation wide and all purposes). All variables are in real terms and in natural log. In parentheses under estimated coefficients are $t$ statistics calculated using the Newey-West method (lag truncation $=4$ ).

(1) Cointegration regression for $\widehat{c a y}(1)$

\begin{tabular}{lccc}
\hline Sample & $f w_{t}$ & $y_{t}$ & Constant \\
\hline Full sample & 0.2125 & 0.5130 & 2.0787 \\
& $(7.58)$ & $(7.96)$ & $(5.68)$ \\
& & & \\
From 1977 & 0.1715 & 0.6125 & 1.5051 \\
& $(4.06)$ & $(5.91)$ & $(2.39)$ \\
\hline
\end{tabular}

(2) Cointegration regression for $\widehat{c a y}(2)$

\begin{tabular}{cccc}
\hline & $a w_{t}$ & $y_{t}$ & Constant \\
\hline Full sample & 0.0705 & 0.8832 & -0.2547 \\
& $(3.10)$ & $(16.89)$ & $(-0.81)$ \\
& & & \\
From 1977 & 0.0747 & 0.8913 & -0.3878 \\
& $(3.86)$ & $(21.57)$ & $(-1.79)$ \\
\hline
\end{tabular}

(3) Cointegration regression for $\widehat{c a y}(3)$

\begin{tabular}{ccccc}
\hline & $f w_{t}$ & $y_{t}$ & $u x_{t}$ & Constant \\
\hline Full sample & 0.2258 & 0.4364 & 0.0495 & 2.5560 \\
& $(5.78)$ & $(5.40)$ & $(2.76)$ & $(6.65)$ \\
From 1977 & 0.2486 & 0.3819 & 0.0377 & 2.9100 \\
& $(3.22)$ & $(2.19)$ & $(1.82)$ & $(3.01)$ \\
\hline
\end{tabular}




\section{Table 2 \\ Descriptive Statistics of $\widehat{c a y s}$ and their Correlations}

See Table 1 for the definitions of $\widehat{c a y}(1), \widehat{c a y}(2)$, and $\widehat{c a y}(3)$.

(1) Correlations between aggregate and per capita $\widehat{c a y} s$

\begin{tabular}{c|cc|cc|cc}
\hline & \multicolumn{2}{|c|}{$\widehat{c a y}(1)$} & \multicolumn{2}{c|}{$\widehat{c a y}(2)$} & \multicolumn{2}{c}{$\widehat{c a y}(3)$} \\
& Full & 1977 & Full & 1977 & Full & 1977 \\
\hline Aggregate Data & & & & & & \\
Mean (\%) & -1.325 & -0.315 & 3.313 & 0.822 & -5.110 & -4.122 \\
S.D. (\%) & 1.535 & 1.454 & 2.713 & 1.656 & 2.118 & 1.924 \\
Autocorrelation & 0.62 & 0.54 & 0.78 & 0.48 & 0.82 & 0.81 \\
& & & & & & \\
Per Capita Data & & & & & & - \\
Mean (\%) & -1.618 & -0.337 & 3.115 & 0.671 & - & - \\
S.D. (\%) & 1.609 & 1.466 & 2.641 & 1.614 & - & - \\
Autocorrelation & 0.68 & 0.53 & 0.77 & 0.46 & - & - \\
Correlation of Aggregate & 0.965 & 0.997 & 0.979 & 0.998 & - & \\
and Per Capita Data & & & & & & \\
\hline
\end{tabular}

(2) Correlation matrix of calculated $\widehat{\text { cay }} \mathrm{s}$

\begin{tabular}{|c|c|c|c|c|c|}
\hline & \multirow{2}{*}{$\begin{array}{c}\widehat{c a y}(1) \\
1977\end{array}$} & \multicolumn{2}{|c|}{$\widehat{\operatorname{cay}}(2)$} & \multicolumn{2}{|c|}{$\widehat{\operatorname{cay}}(3)$} \\
\hline & & Full & 1977 & Full & 1977 \\
\hline$\widehat{c a y}(1)$ : full sample & 0.973 & 0.720 & 0.758 & 0.696 & 0.707 \\
\hline$\widehat{c a y}(1)$ : after 1977 & - & 0.600 & 0.647 & 0.814 & 0.832 \\
\hline$\widehat{\text { cay }}(2)$ : full sample & & - & 0.988 & 0.373 & 0.315 \\
\hline$\widehat{c a y}(3)$ : after 1977 & & & - & 0.420 & 0.371 \\
\hline$\widehat{c a y}(3)$ : full sample & & & & - & 0.993 \\
\hline
\end{tabular}




\section{Table 3 Predicting Future Stock Returns with $\widehat{c a y} \mathrm{~s}$}

Excess returns of TOPIX over the call rate from the end of quarter $t$ to quarter $t+1$, is regressed on the sets of forecasting variables at quarter $t$ for the period of 1977:1Q to 2004:4Q. Additional controls include the following variables: the log price-dividend ratio of TOPIX ( $P D R)$, call rate minus its four-quarter backward moving average (RREL), and yield spread between long-term (10 year) minus short-term (3 months) interest rate (TRM).

(1) $\widehat{c a y}(1)$ series calculated from financial wealth alone

\begin{tabular}{lccccccc}
\hline \hline & Constant & lag & $\widehat{\widehat{c a y}}(1)$ & PDR & RREL & TRM & $\bar{R}^{2}$ \\
\hline 1 & 0.002 & 0.366 & & & & & 0.13 \\
& $(0.25)$ & $(5.52)$ & & & & & \\
2 & 0.132 & & & -0.028 & & & 0.01 \\
& $(1.26)$ & & & $(-1.19)$ & & & 0.02 \\
$3-(1)$ & 0.000 & & -0.916 & & & & \\
& $(0.02)$ & & $(-1.83)$ & & & & 0.13 \\
$4-(1)$ & 0.000 & 0.344 & -0.464 & & & & \\
& $(0.04)$ & $(5.13)$ & $(-1.17)$ & & & & 0.14 \\
$5-(1)$ & 0.124 & 0.354 & -0.303 & -0.027 & & & \\
& $(1.72)$ & $(5.22)$ & $(-0.81)$ & $(-1.67)$ & & & 0.13 \\
$6-(1)$ & -0.001 & 0.325 & -0.509 & & -0.699 & & \\
& $(-0.12)$ & $(5.03)$ & $(-1.26)$ & & $(-1.28)$ & & 0.002 \\
$7-(1)$ & -0.002 & 0.341 & -0.455 & & & 0.12 \\
& $(-0.17)$ & $(5.10)$ & $(-1.20)$ & & & $(0.37)$ & \\
8-(1) & 0.117 & 0.336 & -0.352 & -0.026 & -0.640 & & 0.14 \\
& $(1.66)$ & $(5.12)$ & $(-0.94)$ & $(-1.63)$ & $(-1.36)$ & & \\
$9-(1)$ & 0.122 & 0.336 & -0.371 & -0.026 & -0.773 & -0.003 & 0.13 \\
& $(1.72)$ & $(5.09)$ & $(-1.00)$ & $(-1.63)$ & $(-1.02)$ & $(-0.37)$ & \\
\hline \hline
\end{tabular}




\section{Table 3 (continued)}

(2) $\widehat{c a y}(2)$ series calculated from financial wealth plus SNA real estate data

\begin{tabular}{lccccccc}
\hline \hline & Constant & lag & $\widehat{\operatorname{cay}}(2)$ & PDR & RREL & TRM & $\bar{R}^{2}$ \\
\hline $3-(2)$ & 0.001 & & 0.231 & & & & -0.01 \\
& $(0.14)$ & & $(0.49)$ & & & & \\
$4-(2)$ & 0.001 & 0.366 & 0.154 & & & & 0.12 \\
& $(0.10)$ & $(5.54)$ & $(0.45)$ & & & & \\
$5-(2)$ & 0.136 & 0.370 & 0.130 & -0.030 & & & 0.14 \\
& $(1.77)$ & $(5.93)$ & $(0.35)$ & $(-1.74)$ & & & \\
$6-(2)$ & 0.000 & 0.352 & 0.137 & & -0.634 & & 0.12 \\
& $(-0.02)$ & $(5.24)$ & $(0.40)$ & & $(-1.17)$ & & \\
$7-(2)$ & -0.002 & 0.363 & 0.150 & & & 0.002 & 0.11 \\
& $(-0.18)$ & $(5.74)$ & $(0.43)$ & & & $(0.40)$ & \\
$8-(2)$ & 0.132 & 0.356 & 0.115 & -0.029 & -0.586 & & 0.14 \\
& $(1.74)$ & $(5.58)$ & $(0.31)$ & $(-1.72)$ & $(-1.26)$ & & \\
$9-(2)$ & 0.136 & 0.357 & 0.116 & -0.029 & -0.685 & -0.002 & 0.13 \\
& $(1.82)$ & $(5.54)$ & $(0.32)$ & $(-1.75)$ & $(-0.91)$ & $(-0.28)$ & \\
\hline \hline
\end{tabular}

(3) $\widehat{c a y}(3)$ series calculated from financial wealth and JREI index

\begin{tabular}{cccccccc}
\hline \hline & $\begin{array}{c}\text { Constant } \\
3-(3)\end{array}$ & lag & $\widehat{\widehat{c a y}}(3)$ & PDR & RREL & TRM & $\bar{R}^{2}$ \\
& $(-1.71)$ & & -0.870 & & & & 0.04 \\
$4-(3)$ & -0.017 & 0.329 & $-0.31)$ & & & & \\
& $(-1.05)$ & $(4.15)$ & $(-1.34)$ & & & & 0.13 \\
$5-(3)$ & 0.128 & 0.326 & -0.539 & -0.032 & & & 0.15 \\
& $(1.63)$ & $(4.42)$ & $(-1.50)$ & $(-1.89)$ & & & \\
$6-(3)$ & -0.020 & 0.309 & -0.504 & & -0.729 & & 0.14 \\
& $(-1.19)$ & $(3.97)$ & $(-1.44)$ & & $(-1.28)$ & & \\
$7-(3)$ & -0.024 & 0.318 & -0.522 & & & 0.004 & 0.13 \\
& $(-1.17)$ & $(4.17)$ & $(-1.46)$ & & & $(0.73)$ & \\
$8-(3)$ & 0.122 & 0.307 & -0.578 & -0.032 & -0.688 & & 0.15 \\
& $(1.61)$ & $(4.13)$ & $(-1.52)$ & $(-1.88)$ & $(-1.35)$ & & \\
$9-(3)$ & 0.122 & 0.307 & -0.580 & -0.032 & -0.681 & 0.000 & 0.15 \\
& $(1.63)$ & $(4.15)$ & $(-1.46)$ & $(-1.90)$ & $(-0.91)$ & $(0.02)$ & \\
\hline \hline
\end{tabular}




\section{Table 4 Cross-sectional Regressions with Fama-French Portfolios}

Panel (A) reports average returns of the 25 Fama-French portfolios used in cross-sectional regressions. In Panel (B) and (C), second stage of the FamaMacBeth regressions with 25 Fama-French portfolios are reported. Sample period is the fourth quarter of 1977 to the fourth quarter of 2004. Explanatory variables include value weighted market index (Rvw), Fama-French SMB factor $(S M B)$, and Fama-French HML factor $(H M L)$. The consumption-wealth ratio is included as a lagged conditioning variable $\left(c_{t-1}\right)$. The variable cay(1) corresponds to the $\widehat{c a y}$ series calculated from the cointegration regression using only net financial wealth. cay $(2)$ corresponds to the $\widehat{c a y}$ calculated using SNA real estate data and $\operatorname{cay}(3)$ corresponds to the series calculated from the four variable cointegration regression with the JREI index of urban land prices. All reported $c a y_{t-1}$ coefficients are multiplied by 100 so that $c a y_{t-1}=100 \cdot \widehat{c a y}$.

(A) Average returns (\%) of the 25 Fama-French portfolios

\begin{tabular}{ll|lllll} 
& & \multicolumn{5}{|c}{$\mathrm{B} / \mathrm{P}$} \\
& & 1 & 2 & 3 & 4 & 5 \\
\hline \hline \multirow{4}{*}{ Size } & 1 & 2.16 & 3.59 & 3.57 & 4.08 & 4.06 \\
& 2 & 1.37 & 2.37 & 2.32 & 2.85 & 3.68 \\
& 3 & 1.04 & 1.69 & 2.42 & 2.93 & 3.39 \\
& 4 & 0.96 & 1.74 & 2.15 & 2.75 & 3.16 \\
& 5 & 0.63 & 1.27 & 2.42 & 2.56 & 3.65
\end{tabular}

B/P (book-to-market): $1=$ lowest; $5=$ highest.

Size (firm size): $1=$ smallest; $5=$ largest. 


\section{Table 4 (continued)}

(B) The benchmark models

\begin{tabular}{cccccc} 
& $R v w_{t}$ & $S M B_{t}$ & $H M L_{t}$ & $\Delta y_{t}$ & $R^{2}\left(\bar{R}^{2}\right)$ \\
\hline \hline 1 & -4.3193 & & & & 0.14 \\
& $(-0.17)$ & & & & $(0.06)$ \\
2 & -2.8581 & & & 0.5586 & 0.33 \\
& $(-0.13)$ & & & $(0.10)$ & $(0.24)$ \\
3 & -3.1496 & 0.9149 & & & 0.32 \\
& $(-0.14)$ & $(0.13)$ & & & $(0.23)$ \\
4 & 2.1104 & & 1.8061 & & 0.71 \\
& $(0.08)$ & & $(0.23)$ & & $(0.67)$ \\
5 & 4.5643 & -0.0326 & 2.4851 & & 0.82 \\
& $(0.21)$ & $(-0.01)$ & $(0.38)$ & & $(0.78)$
\end{tabular}

(C) Scaled factor model with different $\widehat{\text { cays }}$

\begin{tabular}{|c|c|c|c|c|c|c|}
\hline & \multicolumn{2}{|c|}{ Factors } & \multicolumn{2}{|c|}{$\widehat{c a y}_{t-1} \cdot$ Factors $_{t}$} & \multirow[b]{2}{*}{$\widehat{c a y}_{t-1}$} & \multirow{2}{*}{$\begin{array}{c}R^{2} \\
\left(\bar{R}^{2}\right)\end{array}$} \\
\hline & $R v w_{t}$ & $\Delta y_{t}$ & $R v w_{t}$ & $\Delta y_{t}$ & & \\
\hline \multicolumn{7}{|c|}{$\widehat{\overline{c a y}}_{t-1}(1):$ net financial wealth } \\
\hline 6-(1) & $\begin{array}{c}0.9335 \\
(0.04)\end{array}$ & $\begin{array}{c}0.2228 \\
(0.05)\end{array}$ & $\begin{array}{c}0.1081 \\
(0.35)\end{array}$ & $\begin{array}{c}-0.0253 \\
(-0.27)\end{array}$ & & $\begin{array}{c}0.44 \\
(0.29)\end{array}$ \\
\hline $7-(1)$ & $\begin{array}{c}3.7975 \\
(0.17)\end{array}$ & $\begin{array}{c}0.1836 \\
(0.04)\end{array}$ & $\begin{array}{c}0.1329 \\
(0.37)\end{array}$ & $\begin{array}{c}-0.0184 \\
(-0.25)\end{array}$ & $\begin{array}{c}-0.0160 \\
(-0.21)\end{array}$ & $\begin{array}{c}0.48 \\
(0.31)\end{array}$ \\
\hline
\end{tabular}

$\widehat{\operatorname{cay}}_{t-1}(2)$ : financial wealth plus SNA real estate data

\begin{tabular}{ccccccc}
\hline $6-(2)$ & -1.9399 & -1.6825 & 0.0118 & -0.0149 & & 0.38 \\
& $(-0.08)$ & $(-0.31)$ & $(0.04)$ & $(-0.19)$ & & $(0.22)$ \\
$7-(2)$ & -5.3308 & -1.0664 & -0.0161 & -0.0022 & 0.0208 & 0.54 \\
& $(-0.21)$ & $(-0.24)$ & $(-0.04)$ & $(-0.03)$ & $(0.28)$ & $(0.38)$
\end{tabular}

$\widehat{\operatorname{cay}}_{t-1}(3)$ : financial wealth and JREI index

\begin{tabular}{ccccccc}
\hline $6-(3)$ & -8.4371 & 0.5162 & 0.1592 & 0.0182 & & 0.50 \\
& $(-0.30)$ & $(0.15)$ & $(0.33)$ & $(0.26)$ & & $(0.36)$ \\
$7-(3)$ & -9.8000 & 1.0128 & 0.1421 & 0.0131 & -0.0194 & 0.69 \\
& $(-0.34)$ & $(0.25)$ & $(0.32)$ & $(0.19)$ & $(-0.24)$ & $(0.59)$
\end{tabular}




\section{Table 5 \\ Scaled Factor and Fama-French Factors}

Scaled factor model with $\operatorname{cay}_{t-1}(3)$ are estimated with Fama-French factors.

See the note for Table 4 for the definitions of variables.

\begin{tabular}{|c|c|c|c|c|c|c|c|c|}
\hline & \multicolumn{3}{|c|}{ Factors } & & \multicolumn{2}{|c|}{$\widehat{\operatorname{cay}}(3)_{t-1} \cdot$ Factors $_{t}$} & \multirow[b]{2}{*}{$\widehat{c a y}_{t-1}$} & \multirow{2}{*}{$\begin{array}{c}R^{2} \\
\left(\bar{R}^{2}\right) \\
\end{array}$} \\
\hline & $R v w_{t}$ & $\Delta y_{t}$ & $S M B_{t}$ & $H M L_{t}$ & $R v w_{t}$ & $\Delta y_{t}$ & & \\
\hline 1 & $\begin{array}{c}-10.7394 \\
(-0.30)\end{array}$ & $\begin{array}{c}-0.2639 \\
(-0.09)\end{array}$ & $\begin{array}{l}0.2786 \\
(-0.04)\end{array}$ & & $\begin{array}{c}0.0963 \\
(0.20)\end{array}$ & $\begin{array}{c}0.0368 \\
(0.44)\end{array}$ & & $\begin{array}{c}0.66 \\
(0.54)\end{array}$ \\
\hline 2 & $\begin{array}{c}3.6796 \\
(0.14)\end{array}$ & $\begin{array}{c}0.3543 \\
(0.10)\end{array}$ & & $\begin{array}{c}2.2955 \\
(0.35)\end{array}$ & $\begin{array}{c}-0.0694 \\
(-0.19)\end{array}$ & $\begin{array}{c}0.0112 \\
(0.16)\end{array}$ & & $\begin{array}{c}0.92 \\
(0.91)\end{array}$ \\
\hline 3 & $\begin{array}{l}4.2067 \\
(0.15)\end{array}$ & $\begin{array}{c}0.3122 \\
(0.08)\end{array}$ & & $\begin{array}{c}2.2825 \\
(0.35)\end{array}$ & $\begin{array}{c}-0.0762 \\
(-0.18)\end{array}$ & $\begin{array}{c}0.0113 \\
(0.16)\end{array}$ & $\begin{array}{c}0.0018 \\
(0.02)\end{array}$ & $\begin{array}{c}0.92 \\
(0.88)\end{array}$ \\
\hline 4 & $\begin{array}{c}3.2230 \\
(0.15)\end{array}$ & $\begin{array}{c}0.3045 \\
(0.10)\end{array}$ & $\begin{array}{c}-0.1686 \\
(-0.02)\end{array}$ & $\begin{array}{c}2.2631 \\
(0.35)\end{array}$ & $\begin{array}{c}-0.0681 \\
(-0.19)\end{array}$ & $\begin{array}{c}0.0127 \\
(0.21)\end{array}$ & & $\begin{array}{c}0.92 \\
(0.88)\end{array}$ \\
\hline
\end{tabular}




\section{Table 6}

\section{Robustness Check}

Subsample estimation results for the fourth quarter of 1977 to the fourth quarter of 2000. See the note for Table 4 for the definitions of variables.

\begin{tabular}{|c|c|c|c|c|c|c|c|c|}
\hline & \multicolumn{3}{|c|}{ Factors } & & \multicolumn{2}{|c|}{$\widehat{\operatorname{cay}}(3)_{t-1} \cdot$ Factors $_{t}$} & \multirow[b]{2}{*}{$\widehat{c a y}_{t-1}$} & \multirow{2}{*}{$\begin{array}{c}R^{2} \\
\left(\bar{R}^{2}\right) \\
\end{array}$} \\
\hline & $R v w_{t}$ & $\Delta y_{t}$ & $S M B_{t}$ & $H M L_{t}$ & $R v w_{t}$ & $\Delta y_{t}$ & & \\
\hline 1 & $\begin{array}{c}-3.2595 \\
(-0.11)\end{array}$ & & & & & & & $\begin{array}{c}0.11 \\
(0.03)\end{array}$ \\
\hline 2 & $\begin{array}{c}-2.3494 \\
(-0.09)\end{array}$ & $\begin{array}{c}-0.5063 \\
(-0.16)\end{array}$ & & & & & & $\begin{array}{c}0.16 \\
(0.04)\end{array}$ \\
\hline 3 & $\begin{array}{c}6.5126 \\
(0.26)\end{array}$ & & $\begin{array}{c}-0.3912 \\
(-0.05)\end{array}$ & $\begin{array}{l}1.8461 \\
(0.29)\end{array}$ & & & & $\begin{array}{c}0.81 \\
(0.77)\end{array}$ \\
\hline 4 & $\begin{array}{c}-7.0766 \\
(-0.23)\end{array}$ & $\begin{array}{c}0.1667 \\
(0.07)\end{array}$ & & & $\begin{array}{c}0.1184 \\
(0.26)\end{array}$ & $\begin{array}{c}0.0111 \\
(0.17)\end{array}$ & $\begin{array}{c}-0.0185 \\
(-0.30)\end{array}$ & $\begin{array}{c}0.64 \\
(0.52)\end{array}$ \\
\hline & $\begin{array}{l}5.8249 \\
(0.22)\end{array}$ & $\begin{array}{c}-0.1746 \\
(-0.08)\end{array}$ & & $\begin{array}{c}1.6902 \\
(0.27)\end{array}$ & $\begin{array}{c}-0.0571 \\
(-0.16)\end{array}$ & $\begin{array}{c}0.0053 \\
(0.09)\end{array}$ & & $\begin{array}{c}0.84 \\
(0.79)\end{array}$ \\
\hline
\end{tabular}




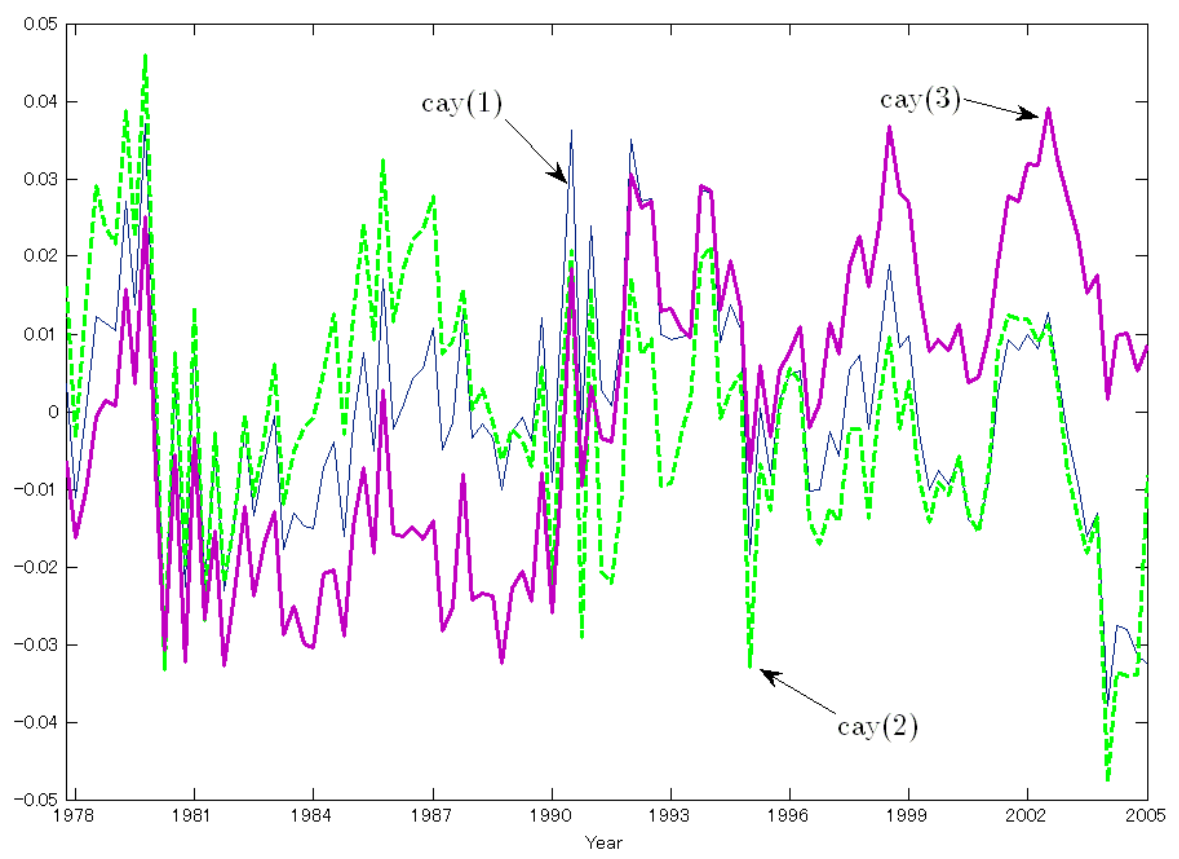

Figure 1: Calculated $\widehat{c a y} \mathrm{~s}$

Plots of $\widehat{c a y}(1), \widehat{c a y}(2)$, and $\widehat{c a y}(3)$ calculated using the estimated cointegrating systems for the subsample starts from 1977 reported in Table 1. All plotted $\widehat{\text { cays }}$ are demeaned. 


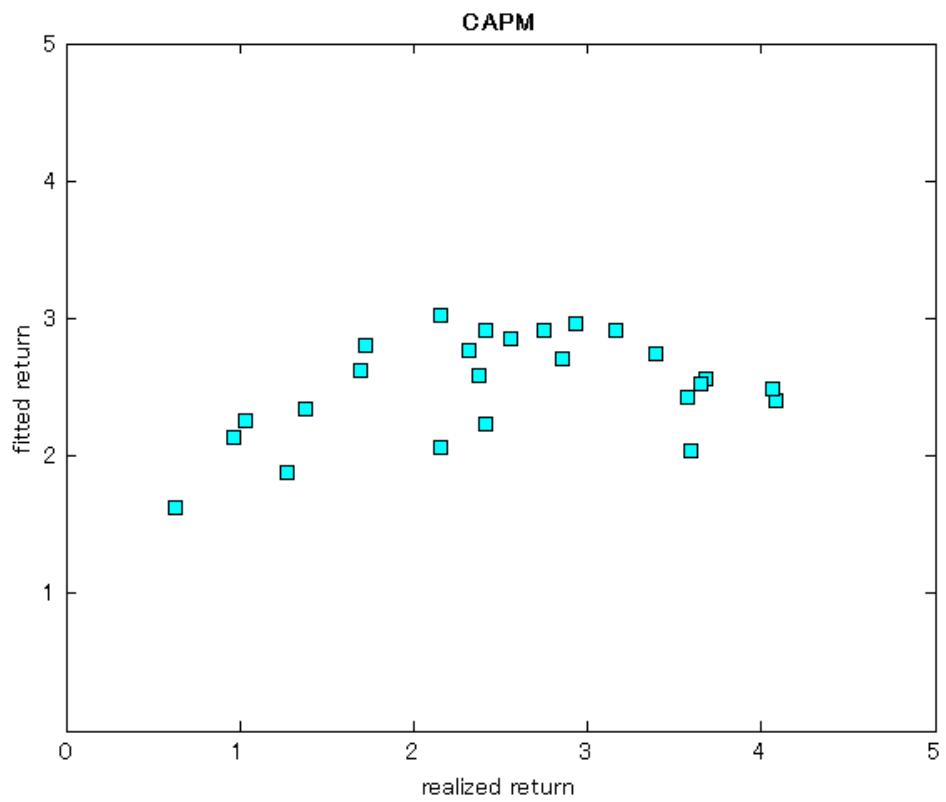

Figure 2: Realized vs Fitted Return: CAPM

Plot of the fitted values of the second-stage Fama-MacBeth regression against actual average returns for the CAPM. Regression results are reported in Table 4, panel (B), row 1. 


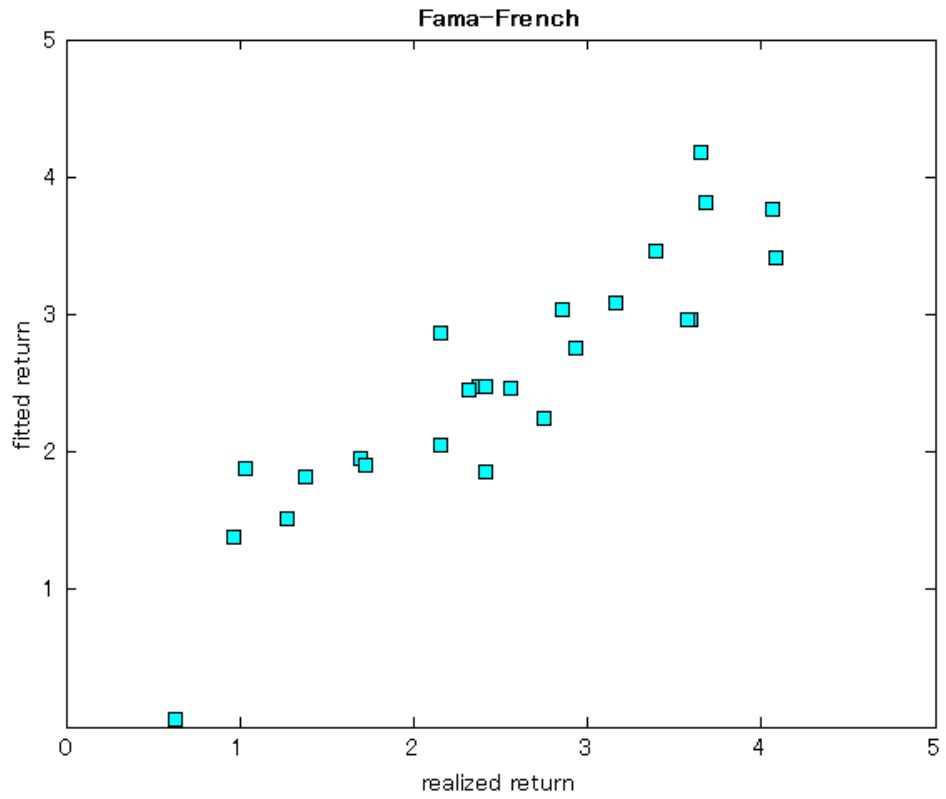

Figure 3: Realized vs Fitted Return: Fama-French

Plot of the fitted values of the second-stage Fama-MacBeth regression against actual average returns for the Fama-French three factor model. Regression results are reported in Table 4, panel (B), row 5. 


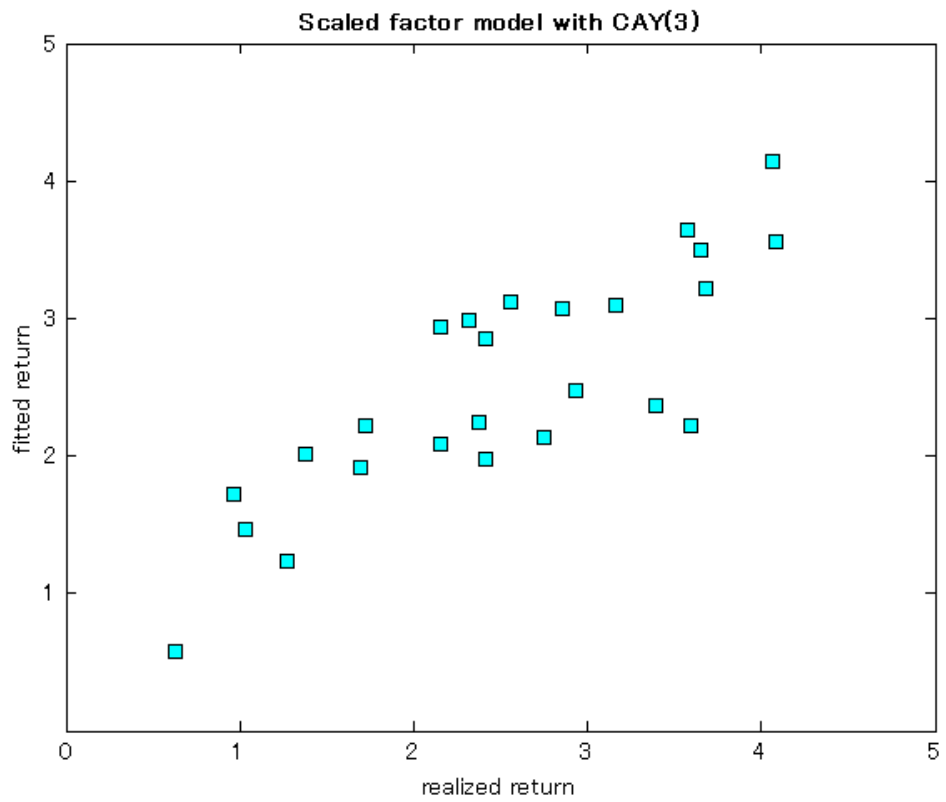

Figure 4: Realized vs Fitted Return: Scaled Factor Model with $\widehat{c a y}(3)$

Plot of the fitted values of the second-stage Fama-MacBeth regression against actual average returns for the scaled factor model using $\widehat{c a y}(3)$ as a scaling variable. Regression results are reported in Table 4, panel (C), row 7-(3). 